\title{
Embracing the Unknown in post-Bertalanffy Systemics Complexity Modeling
}

\author{
Rodolfo A. Fiorini \\ Politecnico di Milano University, Department of Electronics, Information and Bioengineering \\ (DEIB), \\ 32, Piazza Leonardo da Vinci, 20133, Milano, Italy (email: rodolfo.fiorini@polimi.it).
}

\begin{abstract}
Amazing possibility on the one hand and frustrating inaction on the other, that is the yin and yang of modern science (Ness, 2014). The fact that we can build devices that implement the same basic operations as those the nervous system uses leads to the inevitable conclusion that we should be able to build entire systems based on the organizing principles used by the nervous system. Nevertheless, the human brain is at least a factor of 1 billion more efficient than our present digital technology, and a factor of 10 million more efficient than the best digital technology that we can imagine (Fiorini, 2015a). The unavoidable conclusion is that we have something fundamental to learn from the brain and biology about new ways and much more effective forms of computation and information managing. We need revisiting our fundamental research tools and reinventing our scientific ecosystem to enhance relational competence (L'Abate et al., 2010) for real innovation vital development, towards a more sustainable economy and wellbeing (Fiorini et al., 2016). Scientists as well as laymen do ignore evidence incompatible with their preconceptions. We need tools able to manage ontological uncertainty quite more effectively than in the past (Fiorini 2014a, 2014b). In a previous paper, unknown "environmental noise" or/and local "signal input" information have been aggregated to known "system internal control status" information, to provide a self-organizing landscape of self-structuring synthetic attractor points (Fiorini, 2016). This approach, based on the recursive representation of the Computational Information Conservation Theory (CICT) (Fiorini, 2015b), has shown to be quite helpful with high application flexibility. It can be applied at any system scale: from single quantum system application development to full system governance strategic assessment policies (Fiorini, 2016c). It can open the door towards a post-Bertalanffy Systemics Complexity modeling taking into consideration system incompleteness and quasiness and beyond. Scholars have sliced and diced the terms "uncertainty," "ambiguity," and "ignorance," among others, in a variety of different ways (Hanks and Cornell, 1994; Ellsberg, 1961; Ghirardato and Marinacci, 2002). Oftentimes, the usefulness of these sharp lines is not plainly apparent. But one dividing line between types of unknowns, i.e. the distinction between risk and ambiguity, has recently led researchers to fascinating new biological insights (Alary et al., 2010). We have something fundamental to learn from the
\end{abstract}


brain and biology about new and much more effective form of computation to develop more effective and antifragile system (Taleb, 2013). Evidence from brain science has shown that the amygdala and the orbitofrontal cortex (OFC) are more active when people face ambiguous odds rather than merely risky ones, suggesting that ambiguity is fundamentally more emotional (Goleman, 1995; Bechara et al., 2000; Ledoux, 2002; Ward et al., 2015). Even when precise odds exist, if they are unknown, as they often are in everyday decision making, then we treat the decision as ambiguous. Our preference for clear odds may have deep evolutionary roots. The OFC represents one critical structure in a neural system subserving decision making. Decision making is not mediated by the orbitofrontal cortex alone, but arises from large-scale systems that include other main cortical and subcortical components. Such structures include the amygdala, the somatosensory/insular cortices, peripheral nervous system and the ventromedial prefrontal sector. The ventromedial sector includes both the gyrus rectus and mesial half of the orbital gyri, as well as the inferior half of the medial prefrontal surface, from its most caudal aspect to its most rostral in the frontal pole (Bechara et al., 2000). Damage to the ventromedial sector disrupts social behavior profoundly. Previously well-adapted individuals become unable to observe social conventions and unable to decide advantageously on matters pertaining to their own lives. Remarkably, the subject's intellectual abilities are generally well preserved, in the sense that they have normal learning and memory, language and attention, and they even perform normally on many so-called executive function tests, such as the Wisconsin Card Sorting Test (WCAT) (Berg, 1948). Our means of new knowledge is reason, the use of observation and logic to learn and prosper. As a matter of fact, in logic, (a) the needs of the healthy individual are what give rise to the need and possibility of value judgments to begin with; and (b) there can be no divide between acting logically and acting human (Fiorini, 2018). CICT new awareness of a discrete HG (hyperbolic geometry) subspace (reciprocal space) of coded heterogeneous hyperbolic structures, underlying the familiar $\boldsymbol{Q}$ Euclidean (direct space) surface representation can open the way to recover lost coherence information in system description (Fiorini, 2017). CICT can help us to develop strategies to gather much more reliable experimental information from single experimentation and to keep overall system computational information coherence. Application examples are discussed. The present paper is a relevant contribute towards a post-Bertalanffy Systemics Complexity modeling proposal.

\section{References}

Alary, D., Gollier, C.G., Treich, N. (2010). The effect of ambiguity aversion on risk reduction and insurance demand, March 15, 2010. Available at:

$<$ http://www.economics.unsw.edu.au/contribute2/Economics/news/documents/NicolasApri10 .pdf $>$.

Bechara, A., Damasio, H., Damasio, A.R. (2000). Emotion, Decision Making and the Orbitofrontal Cortex. Cereb. Cortex, 10(3):295-307. 
Berg, E.A. (1948). A simple objective technique for measuring flexibility in thinking. J. Gen. Psychol., 39:15-22.

Ellsberg, D. (Nov. 1961). Risk, Ambiguity, and the Savage Axioms. The Quarterly Journal of Economics, 75(4):643-669.

Fiorini, R.A.(2014a). Stronger Physical and Biological Measurement Strategy for Biomedical and Wellbeing Application by CICT. In N.E. Mastorakis, A. Fukasawa (Eds.), Recent Advances in Biology and Biomedicine Series No.6, (pp.36-45). WSEAS Press, 3rd Intntl. Conf. on Health Science and Biomedical Systems (HSBS '14), Nov. 22-24, 2014, Florence, Italy.

Fiorini, R.A. (2014b). Stronger Quantum Decoherence Incomputability Modeling by CICT. In N.E. Mastorakis, G.Q. Xu (Eds.), Mathematics and Computers in Science and Engineering Series No.39, (pp.78-86). WSEAS Press, 3rd International Conference on Applied and Computational Mathematics (ICACM '14), December 29-31, 2014, Geneva, Switzerland.

Fiorini, R.A. (2015). Brain Modeling, Spacetime Splitting and Computer Science. In X. Zhuang (Ed.), Recent Advances in Computer Engineering Series n.35, (pp.142-151). WSEAS Press, $6^{\text {th }}$ European Conference on Computer Science (ECCS '15), Nov. 7-9, 2015, Rome, Italy.

Fiorini, R.A. (2015). More effective biomedical experimentation data by CICT advanced ontological uncertainty management techniques. Int. J. of Biol and Biomed Eng, 9:29-41.

Fiorini, R.A. (2016). From systemic complexity to systemic simplicity: a new networking node approach. In G.F. Minati, M. Abram, E. Pessa (Eds.), Towards a Post-Bertalanffy Systemics (pp. 97-108). Switzerland, CH: Springer International Publishing.

Fiorini, R.A. (2016c). Quantum cognitive computation by CICT. In Y. Wang, B. Widrow, L. A Zadeh (Eds.), Proc. 15th IEEE International Conference on Cognitive Informatics \& Cognitive Computing (pp.60-71). IEEE ICCI'CC'16, August 22-23, 2016. Stanford, CA: Stanford University.

Fiorini, R.A. (2017). Brain-Inspired Systems and Predicative Competence. 16th IEEE International Conference on Cognitive Informatics \& Cognitive Computing, ICCI*CC 2017, Oxford, UK, July 26-28, 2017.

Fiorini, R.A. (2018). Logic and Order: Ontologic Effective Management for Learning and Creativity. In J. Horne (Ed.), Philosophical Perceptions on Logic and Order, Chap11, (pp. 283351). A volume in the Advances in Knowledge Acquisition, Transfer, and Management (AKATM) Book Series. Hershey PA, USA: IGI Global.

Fiorini, R.A., De Giacomo, P., L'Abate, L. (2016). Wellbeing Understanding in High Quality Healthcare Informatics and Telepractice. In Mantas, J., Hasman, A., Gallos, P., Kolokathi, A., Househ, M.S. (Eds.), Studies in Health Technology and Informatics, 226, (pp.153-156). IOS Press.

Ghirardato, P., Marinacci, M. (2002). Ambiguity Made Precise: A Comparative Foundation. Journal of Economic Theory, 102:251-289.

Goleman, D.J., (1995). Emotional Intelligence: Why It Can Matter More Than IQ. New York: Bantam Books.

Hanks,T.C., Cornell, C.A. (1994). Probabilistic Seismic Hazard Analysis: A Beginner's Guide. In Proc.Fifth Symposium on Current Issues Related to Nuclear Power Plant Structures, Equipment and Piping, (pp.I/1-1 to I/1-17). Raleigh, N.C., USA: North Carolina State Univ.

L'Abate, L., Cusinato, M., Maino, E., Colesso, W., Scilletta, C. (2010). Relational Competence Theory. New York, NY, USA: Springer-Verlag.

Ledoux, J., (2002). Synaptic Self, How Our Brains Become Who We Are. New York, N.Y., USA: Viking Penguin.

Ness, R.B. (2014). The Creativity Crisis. Oxford, UK: Oxford University Press.

Ward, R.D., Winiger, V., Kandel, E.R., Balsam, P.D., Simpson, E.H. (2015). Orbitofrontal cortex mediates the differential impact of signaled-reward probability on discrimination accuracy. Front. Neurosci., 23 June 2015.

Taleb, N.N., Douady, R., (2013). Mathematical definition, mapping, and detection of (anti) fragility. Quantitative Finance, 13(11):1677-1689. 